Journal of Engineering Science and Technology Review 8 (1) (2015) 1 -7

Special Issue on Econophysics

Conference Article

\section{JOURNAL OF}

Engineering Science and

Technology Review

\title{
The Effect of Foreign Direct Investment in Economic Growth from the Perspective of Nonlinear Dynamics
}

\author{
Ch. K. Volos*, I. M. Kyprianidis and I. N. Stouboulos
}

Physics Department, Aristotle University of Thessaloniki, GR-54124, Greece

\begin{abstract}
In today's globalized economy one of the most crucial factors for the economic growth of a country, especially of a developing country, is the foreign direct investment, not only because of the transfer of capital but also of technology. In this work, the effect of foreign direct investments in a county's economic growth by using tools of nonlinear dynamics is studied. As a model of the economic growth of a country, a well-known nonlinear discrete-time dynamical system, the Logistic map, is used. The system under study consists of two countries with a strong economic relationship. The source country of foreign direct investments is an industrialized, economically powerful and technologically advanced country that makes significant investments in the host country, which is a developing country and strong dependent from the source country. Simulation results of system's behavior and especially the bifurcation diagrams reveal the strong connection between the countries of the proposed system and the effect of foreign direct investments in the economic growth of the host country.
\end{abstract}

Keywords: Foreign direct investment, economic growth, chaos, Logistic map, bifurcation diagram, Lyapunov exponent.

\section{Introduction}

The end of the Second World War caused political and economical upheavals worldwide, out of which came a new bipolar system. Also, the world population since 1950 has rapidly increased especially in developing countries. This growth has been matched by more rapid increases in gross domestic product, and thus income per capita has increased in most countries around the world since then. By the end of the cold war in the early $90 \mathrm{~s}$, there was an enlarged trend movement of capital and manpower because of the freedom that the new system provided. Moreover, the rapid development of new technologies has contributed to this new globalized economic system that dominates today.

In this context, the foreign direct investments in countries especially from developed countries to developing ones have rapidly increased. Foreign Direct Investment (FDI) is a direct investment into production or business in a country by a company from another country, either by buying a company in the target country or by expanding operations of an existing business in that country. Foreign direct investment is in contrast to portfolio investment, which is a passive investment in the securities of another country such as stocks and bonds.

A great number of studies on this subject have made useful contributions to understanding the role of FDI in economic growth. The analysis, by many researchers, of the effects of FDI in developing and transition countries suggests that foreign investment increases local productivity growth. Also, the role of FDI in the process of technology diffusion in these countries is very important for the economic growth [1]. Nevertheless, the effect of FDI in the growth-enhancing

\footnotetext{
*E-mail address: chvolos@gmail.com

ISSN: 1791-2377 @ 2015 Kavala Institute of Technology. All rights reserved.
}

appears to depend on host country's specific characteristics, such as human capital conditions, minimum threshold stock, liberalized trade regime and macroeconomic stability [2].

The purpose of this work is to examine the role of foreign direct investment in the process of economic growth especially in developing countries by using the well-known nonlinear model of the Logistic map and some tools of nonlinear theory, especially the Lyapunov exponent and the bifurcation diagram. So, this paper presents a relatively simple chaotic economic growth model of two strongly connected economies, a developed which is the source of FDI and a developing one, which is the host of FDI. It is known, that chaos theory and nonlinear dynamics have been applied in economics from many research teams until today to explain various phenomena [3].

This paper is organized as follows. In Section 2, the notion of chaotic dynamical systems and the features of these systems are referred. The known discrete-time dynamical system, the Logistic map, is presented in Section 3. Section 4 describes the proposed model of a country's economic growth, by using the Logistic map. The effect of foreign direct investment in economic growth, in the case of a system of two strongly connected countries, is studied in Section 5. Section 6 presents the simulation results of system's behavior. Finally, Section 7 includes the conclusions of this work.

\section{Chaotic Systems}

Although, the first observation of chaotic systems was made by the French Mathematician Henri Poincaré at the end of the 19th century [4], the chaos theory begins to take form in the second half of the 20th century after observations of the 
evolution of different physical systems [5]. These systems revealed that despite of the knowledge of their evolution rules and initial conditions, their future seemed to be arbitrary and unpredictable. That opened quite a revolution in modern

physics, terminating with Laplace's ideas of casual determinism [6].

From that time, chaos has been observed in various systems such as weather and climate [5], population growth in ecology [7], economy [8], to mention only a few examples. It also has been observed in the laboratory in a number of systems such as electrical circuits [9], lasers [10], chemical reactions [11], fluid dynamics [12], mechanical systems, and magneto-mechanical devices [13]. So, chaos theory provides the means to explain various phenomena not only in nature but also in laboratory and make use of chaotic dynamical systems in many different scientific fields.

In general, Chaos theory studies a dynamical system that evolves in time, presenting three very important features [14]. It must be topologically mixing, its periodic orbits must be dense and it must be very sensitive on initial conditions.

The first term, the topological mixing, means that the chaotic trajectory at the phase space will move over time so that each designated area of this trajectory will eventually cover part of any particular region. The second feature of chaotic systems, the fact that its periodic orbits have to be dense, means that the trajectory of a dynamical system is dense, if it comes arbitrarily close to any point in the domain. Furthermore, the third and probably the most important feature of chaotic systems, is the sensitivity on initial conditions. This means that a small variation on a system's initial conditions will produce a totally different chaotic trajectory.

As it is known, a dynamical system describes a physical phenomenon that evolves in time. In mathematical terms, the states of the system are described by a set of variables and its evolution is given by a set of differential equations (Eq.(1)) with the values of the initial states.

$$
\frac{\mathrm{d} X_{i}(t)}{\mathrm{d} t}=F_{i}\left(X_{j}(t), \Lambda\right)
$$

$X_{i}(t) \in R^{N}$ is the coordinate $i$ of the state of the system at instant time $t$, that is $X$ is an $N$-dimensional vector, $i, j=1$, $\ldots, N$ with $N \geq 1, F$ is a parametric nonlinear function that describes the evolution of the system and $\Lambda$ is the vector of parameters that control the evolution of the system. It is observed that this kind of systems is deterministic, thus the time evolution of $X$ can be calculated with $F$ and $\Lambda$ from a given initial state $X_{0}$. In continuous-time dynamical systems, $t$ takes continuous values, corresponding to the evolution of the system's dynamic behavior in time.

On the other hand, the discrete-time dynamical systems are described by the following equation:

$$
X_{i(t+1)}=F_{i}\left(X_{j t}, \Lambda\right), j=1,2, \ldots, N ; t=0,1,2, \ldots, T
$$

Apparently, Eq.(2) describes also deterministic systems where the discrete time's evolution of $X$ can be calculated with $F$ and $\Lambda$ for a given initial state $X_{0}$. These systems are also recursive as the next state is calculated from the previous one. The dynamical system which has been used in this work and presented in details in the next section belongs to this class of dynamical systems.

\section{The Logistic Map}

One of the most studied discrete-time dynamical systems is the Logistic map, which is described by the following iterative equation.

$x_{\mathrm{t}+1}=r x_{t}\left(1-x_{t}\right), \quad 0 \leq x \leq 1$

This occurs because of its simplicity in form and the appearance of all the well-known features of chaotic systems. These are the reasons why it has found application in various scientific fields. The Logistic map was popularized in a seminal paper by the biologist Robert May [15], in part as a discrete-time demographic model analogous to the logistic equation first created by Pierre François Verhulst [16]. Since then, the Logistic map has been used in biophysical systems [17], cryptography [18], thermodynamics [19], economy [20], to name few.

As, it shown in Eq.(3) the Logistic map has a parameter $r$ which varies in the interval $[0,4]$ so that the one-dimensional variable $x_{t}$ maps the unit interval into the unit interval. This is clearly observed in Fig.1(a) in which the map function of $x_{t+1}$ as a function of $x_{t}$, for $r=4$ and $x_{0}=0.5$, is shown. Additionally, from this plot the symmetry of the Logistic map about the mid point of the interval $[0,1]$ is concluded.

By studying the Logistic map the following regions, depending on the value of $r$, may be considered.

- For $r<1, x$ decays to a fixed point $(x \rightarrow 0)$.

- For $1 \leq r<3$, the previous fixed point loses its stability and another fixed point $(x=1-1 / r)$ appears.

- For $3 \leq r \leq 4$, the Logistic map presents a more complex behavior (such as repeated period doublings, appearance of odd periods e.t.c.) which finally leads to chaos.

In Fig.1(b) the so-called "Bifurcation diagram", which is also a very common perspective in nonlinear dynamics, in the range of $r \in[2.5,4]$ is shown. In more details, this diagram produced by plotting the steady-state behavior of Eq.(3) with respect to the bifurcation parameter $r$. So, it serves to illustrate the rich dynamical behavior of the Logistic map showing among the other the very interesting "perioddoubling" route from periodic to chaotic behavior [15].

The first bifurcation, as it is shown in Fig.1(b), occurs at the value of $r=3$, followed by further doublings at shorter and shorter intervals of $r$ until the period goes to infinity at $r_{\infty}$ $=3.5699 \ldots$, signifying chaos. Also, various periodic windows interspersed beyond $r_{\infty}$, are observed, in which the behavior returns to a normal periodic one, quickly followed again by bifurcations to an infinite period. So, for values of $r$ greater than $r_{\infty}=3.5699 \ldots$ the Logistic map shows a strange complex behavior (the so-called chaotic behavior) where map function never repeats its history.

In Fig.2, another useful tool of nonlinear theory, the wellknown Lyapunov exponent [21]:

$$
\lambda=\lim _{t \rightarrow \infty} \sum_{i=1}^{t} \ln \left|f^{\prime}\left(x_{i}\right)\right|
$$

where,

$f^{\prime}(x)=r-2 r x$ 
as a function of parameter $r$, is displayed. According to the nonlinear theory a positive Lyapunov exponent indicates chaos. So, Fig.2 confirms the Logistic map's dynamical behavior as found from the bifurcation diagram of Fig.1(b).
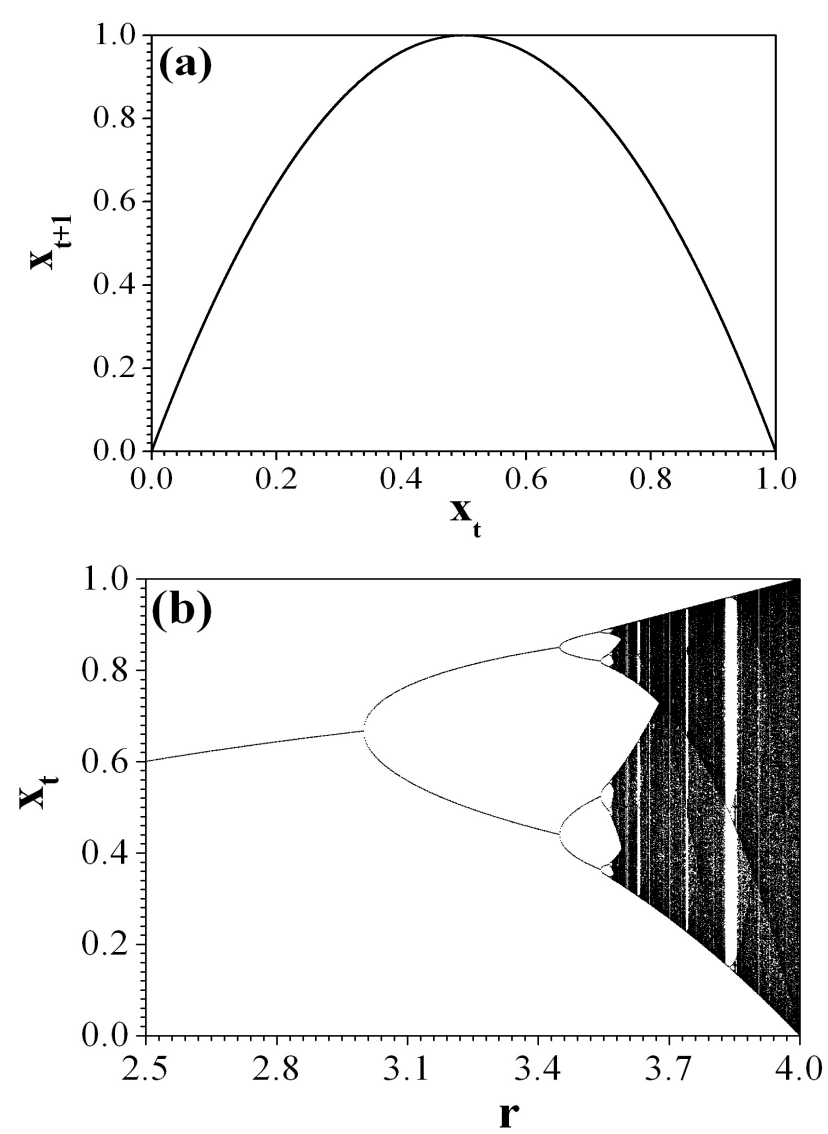

Fig. 1. (a) The map function of the Logistic equation (3), for $r=4$ and $x_{0}$ $=0.5$ and (b) the bifurcation diagram of $x_{t}$ versus the parameter $r$ of the Logistic map of Eq.(3).

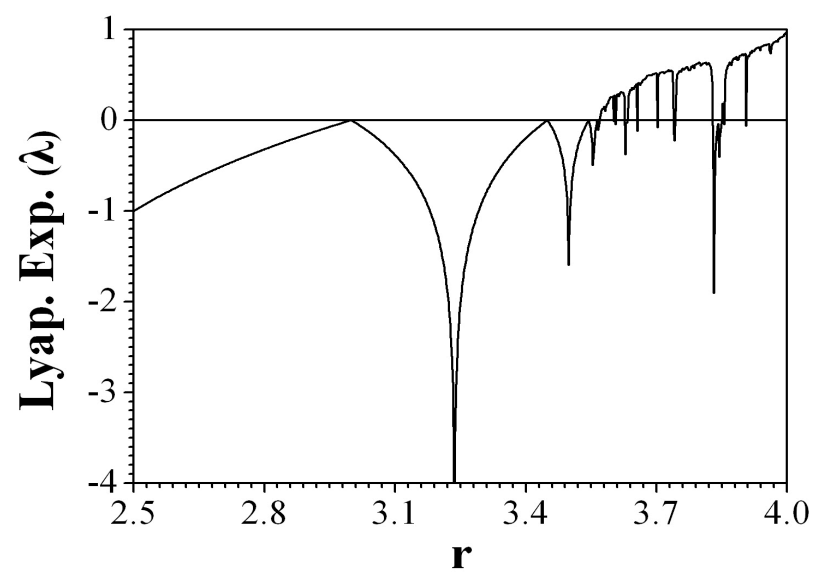

Fig. 2. The diagram of Lyapunov exponent $(\lambda)$ vs. parameter $r$.

\section{The Economic Model}

In this work the model for the economic growth, which has been proposed by Jablanovic [20], is adopted. This model is based on the following equations.

$p_{m}=\frac{\Delta y}{\Delta L}$
$S_{t}=S_{p t}-B d_{t}$

$S_{t}=I_{t}+N C O_{t}$

$S_{p t}=s y_{t}$

$I_{t}=K_{t+1}$

$y_{t}=\sqrt{L_{t}}$

$k=K_{t} / L_{t}$

$N C O_{t}=n y_{t}$

$B d_{t}=b y_{t}$

In more details, Eq.(6) defines the marginal labour productivity coefficient $\left(p_{m}\right)$, where $(y)$ is the Gross Domestic Product (GDP) and $(L)$ the labour. Also, $(y)$ is in normalized units so as it ranges between zero and one. For this reason the $(y)$ is introduced as $y=Y_{t} / Y_{\max }$, where $\left(Y_{\max }\right)$ is the maximum value of the real gross domestic product $\left(Y_{t}\right)$. Eq.(7) defines the national saving $(S)$ in regard to private saving $\left(S_{p}\right)$ and budget deficit $\left(B_{d}\right)$. Eq.(8) describes the relation between saving $(S)$ and investment $(I)$ plus the net capital outflow $(N C O)$. Eq.(9) determines the private saving, where $(s)$ is the private saving rate. Investment $(I)$ is a function of the capital $(K)$ as shown in Eq.(10). Eq.(11) defines the production function while in Eq.(12) the parameter $(k)$ is the capital coefficient. Eq.(13) determines the net capital outflow $(N C O)$, where $(n)$ is the net capital outflow rate. Finally, Eq.(14) defines the budget deficit $\left(B_{d}\right)$, where $(b)$ is the budget deficit rate.

By using Eqs.(6)-(14) one derives the following equation.

$y_{t+1}=\frac{k+p_{m}(s-b-n)}{k} y_{t}-p_{m} y_{t}^{2}$

The above mentioned Eq.(15) is equivalent to the Logistic map of Eq.(3), using:

$$
x_{t}=\frac{p_{m} k}{k+p_{m}(s-b-n)} y_{t}, r=\frac{k+p_{m}(s-b-n)}{k}
$$

\section{The Model of Effect of Foreign Direct Investment in Economic Growth}

One of the more crucial factors in economic growth of a country, especially of a developing country, is the Foreign Direct Investment (FDI). This occurs because FDI is in fact a vehicle for the transfer not only of capitals from one country to another but also of technology. It appears that the main channel through which FDI contributes to economic growth is by stimulating technological progress, rather than by increasing total capital accumulation in the host economy. So, FDI increases the rate of technical progress in the host country through a "contagion" effect from the more advanced technology used by the foreign firms [22] and also contributes to the increase in "knowledge" applied to production in the host country [23]. However, there is a 
robust relationship between economic growth, FDI and human capital [24]. This means that the application of these more advanced technologies via FDIs also require the presence of a sufficient level of human capital in the host economy.

In this work, the role of foreign direct investment, from a source country (A) to a host country (B), in the process of economic growth especially in the case that the host country is a developing country, is studied. In more details, the case of two countries with a strong economic relationship among them is considered. The source country (A) is an industrialized, economically powerful and technologically advanced country that makes significant as a percentage of GDP, investments in the host country (B), which is a developing country and strong dependent from (A). Foreign direct investment taking place between countries with roughly the same level of technological development may respond to a large extent to other factors, including global firm strategy and market penetration, or to allow firms to circumvent trade restrictions and offset other advantages accorded to domestic producers. This type of foreign direct investment flows may not be expected to display higher than average productivity. For this reason we focus only on foreign direct investments received by a developing country. And furthermore, since flows of foreign direct investments between developing countries may also respond to factors other than the technological gap, we also exclude those flows.

Like many other interesting problems, interaction between economies can be described by the dynamics of coupled oscillators. So, the following system (Eqs.(17) \& (18)) of two linearly coupled Logistic maps of Eq.(15) is considered.

$$
\begin{aligned}
& \text { (A): } x_{t+1}=r_{\mathrm{A}} x_{t}\left(1-x_{t}\right)-\xi_{\mathrm{A}} r_{\mathrm{A}} x_{t}\left(1-x_{t}\right)+\xi_{\mathrm{B}} r_{\mathrm{B}} y_{t}\left(1-y_{t}\right) \\
& \text { (B): } y_{t+1}=r_{\mathrm{B}} y_{t}\left(1-y_{t}\right)-\xi_{\mathrm{B}} r_{\mathrm{B}} y_{t}\left(1-y_{t}\right)+\xi_{\mathrm{A}} r_{\mathrm{A}} x_{t}\left(1-x_{t}\right)
\end{aligned}
$$

$x, y$ is the gross domestic products of countries (A) and (B), respectively. The second term in each of these two equations is the outflow of FDI from countries (A) and (B), while the third term is the inflow of FDI from country (B) and (A) respectively, as a rate $(\xi)$ of the gross domestic product. Due to the fact that the country (B) is considered as a developing country its FDIs to the country (A) is equal to zero, so $\xi_{\mathrm{B}}=0$. For this reason the aforementioned system of Eqs.(17) \& (18) is finally become:

$$
\begin{aligned}
& \text { (A): } \quad x_{t+1}=\left(1-\xi_{\mathrm{A}}\right) r_{\mathrm{A}} x_{t}\left(1-x_{t}\right) \\
& \text { (B): } y_{t+1}=r_{\mathrm{B}} y_{t}\left(1-y_{t}\right)+\xi_{\mathrm{A}} r_{\mathrm{A}} x_{t}\left(1-x_{t}\right)
\end{aligned}
$$

\section{Simulation Results}

In this section the simulation results of the system of the two interacting economies of Eqs.(19) \& (20), are studied. In the following, the Logistic map's parameter $\left(r_{\mathrm{A}}\right)$ and $\left(r_{\mathrm{B}}\right)$ is fixed in various values, in order to cover as many cases of dynamic behaviors as possible. Especially, the parameter $\left(r_{\mathrm{A}}\right)$ of the logistic map representing the economy of country (A) is chosen always higher than $\left(r_{\mathrm{B}}\right)$ of the country $(\mathrm{B})$, based on the assumption that country $(\mathrm{A})$ is economically stronger than country (B). Also, the parameter $\left(\xi_{\mathrm{A}}\right)$ plays the role of the control parameter which may range from zero to one.
However, the FDI of one country to another, as a percentage of its gross domestic product, could not have very high value. Thus, this study is limited in the range of $\xi_{\mathrm{A}} \in[0,0.1]$, but in many cases, this range has been expanded to display several interesting dynamic phenomena.

In the first case the value of the parameter $\left(r_{\mathrm{A}}\right)$ is chosen equal to 4 , in order that the Logistic map representing the economy of country (A) is in the chaotic region, while the parameter $\left(r_{\mathrm{B}}\right)$ takes values lower than $\left(r_{\mathrm{A}}\right)$ according to the values of Table 1. Fig.3(a) shows the bifurcation diagram of $\left(x_{t}\right)$ versus the control parameter $\left(\xi_{\mathrm{A}}\right)$ in the case of $r_{\mathrm{A}}=4$, which is a reverse of the known Logistic map of Eq.(3) (Fig.1(b)). This occurs, because there are no flow of FDI from country (B) to country (A) while the only differentiation from the Logistic map is the factor $\left(1-\xi_{A}\right)$ in Eq.(19). So, the economic system of the first country $(\mathrm{A})$ has for low values of $\left(\xi_{\mathrm{A}}\right)$ chaotic behavior $\left(\xi_{\mathrm{A}} \in[0,0.107]\right)$ and following the reverse period-doubling route ends up in a period-1 steady state.

In Fig. 4 the six bifurcation diagrams of the gross domestic product $\left(y_{t}\right)$ of country (B) versus the control parameter $\left(\xi_{\mathrm{A}}\right)$ in the case of Eq. (20) for the selected values of $\left(r_{\mathrm{B}}\right)$ of Table 1 , are shown. In all cases the economy of country (B) begins, for $\xi_{\mathrm{A}}=0$, of its dynamic state, which is indicated by the chosen value of $\left(r_{\mathrm{B}}\right)$, and under the influence of the chaotic behavior of economy (A) enters into chaotic regions for low values of $\left(\xi_{\mathrm{A}}\right)$. Also, the chaotic regions are interrupted by windows of periodic behavior as it is always occurrs in chaotic systems like the above.

In more details, when the GDP of country (B) is in a period-1 steady state $\left(r_{\mathrm{B}}=2.00\right)$, is strongly influenced by the GDP of country (A), as its bifurcation diagram of Fig.4(a) shows the same behavior with the bifurcation diagram of Fig.3(a) of the GDP of country (A), for the same values of the control parameter $\left(\xi_{\mathrm{A}}\right)$.

So, the GDP of country (B) via the reverse period doubling route ends up in a period-1 steady state like the economy (A). When the GDP of country (B) is initially at a period-2 steady state $\left(r_{\mathrm{B}}=3.20\right)$, two branches with the same dynamic behavior for the same regions of the control parameters are displayed in the bifurcation diagram of Fig.4(b). This occurs for $\left(\xi_{\mathrm{A}}<0.169\right)$ while after this value the phenomenon of "crisis" [25] occurs and the system suddenly changes its dynamic behavior from chaotic to periodic.

The same behavior but on a smaller scale is displayed on the bifurcation diagram of Fig.4(c), for $r_{\mathrm{B}}=3.50$ (period-4 steady state). Also, in this diagram after an extended region of chaotic behavior the well-known phenomenon of creating an "inverse bubble" of period-4 occurs in the window of $\xi_{A} \in[0.103,0.133]$. Finally, in Figs.4(d)-(f) the GDP of country (B) always has a chaotic behavior except of small windows of periodic behavior which interrupt the previous one.

Table 1. Chosen values for the parameter $r_{\mathrm{B}}$ of the Logistic map.

\begin{tabular}{ll}
\hline $\boldsymbol{r}_{\mathbf{A}, \mathbf{B}}$ & Dynamic Behavior \\
\hline 2.00 & Period-1 limit cycle \\
3.20 & Period-2 limit cycle \\
3.50 & Period-4 limit cycle \\
3.60 & Chaos \\
3.63 & Period-6 limit cycle \\
3.70 & Chaos \\
\hline
\end{tabular}



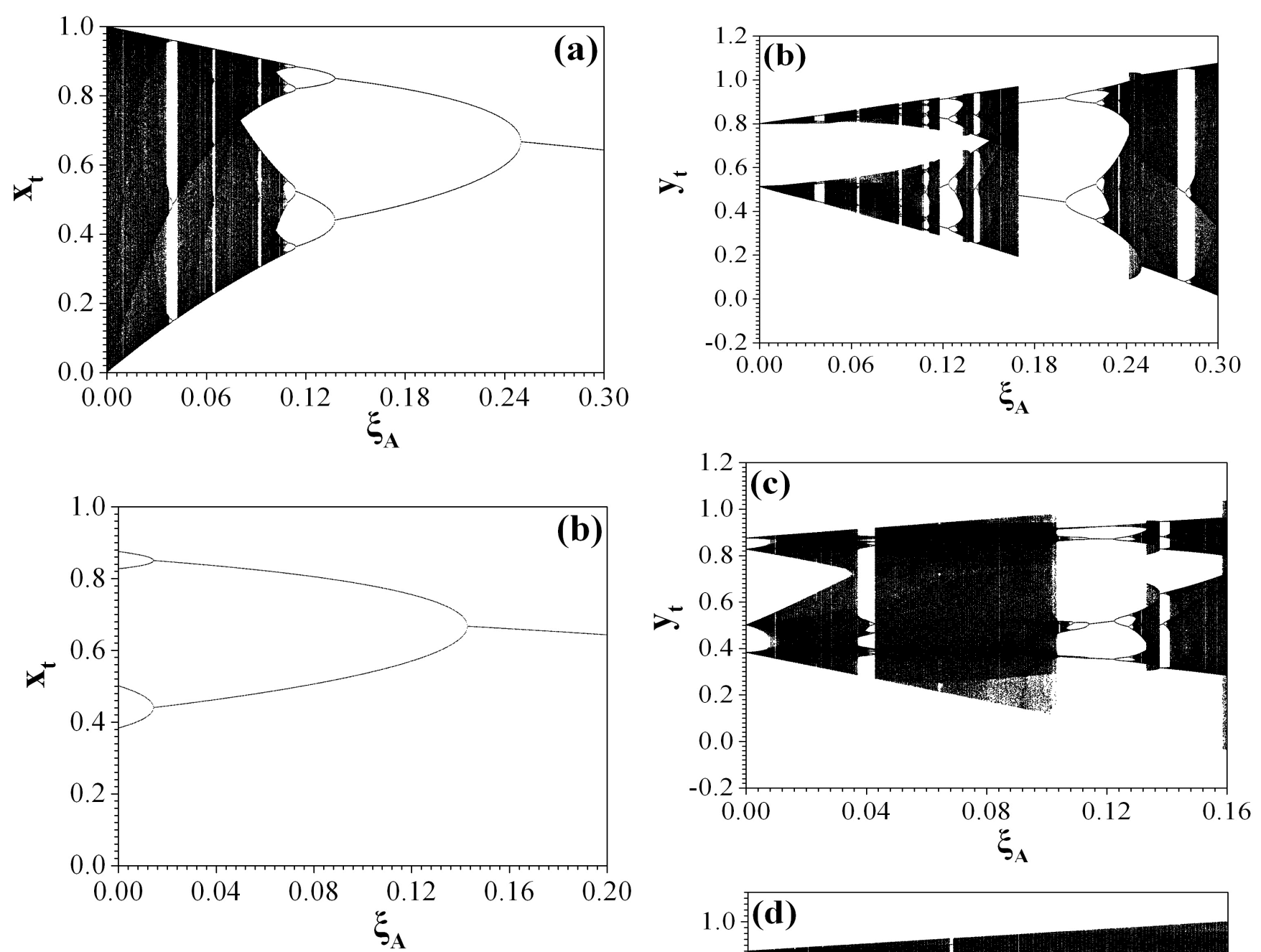

Fig. 3. Bifurcation diagrams of $x_{t}$ versus the control parameter $\xi_{\mathrm{A}}$, in the cases of (a) $r_{\mathrm{A}}=4$ and (b) $r_{\mathrm{A}}=3.5$.

In the second case the value of the parameter $\left(r_{\mathrm{A}}\right)$ is chosen equal to 3.50 so that the GDP of country (A) is in periodic state and specifically in period-4 steady state. Fig.3(b) shows the bifurcation diagram of $\left(x_{t}\right)$ versus the control parameter $\left(\xi_{\mathrm{A}}\right)$, in the case of $r_{\mathrm{A}}=3.50$. As it is shown, the GDP of country (A) begins from a period-4 state and via the reverse period doubling route ends up for $\xi_{\mathrm{A}}>$ 0.143 into a period- 1 steady state.
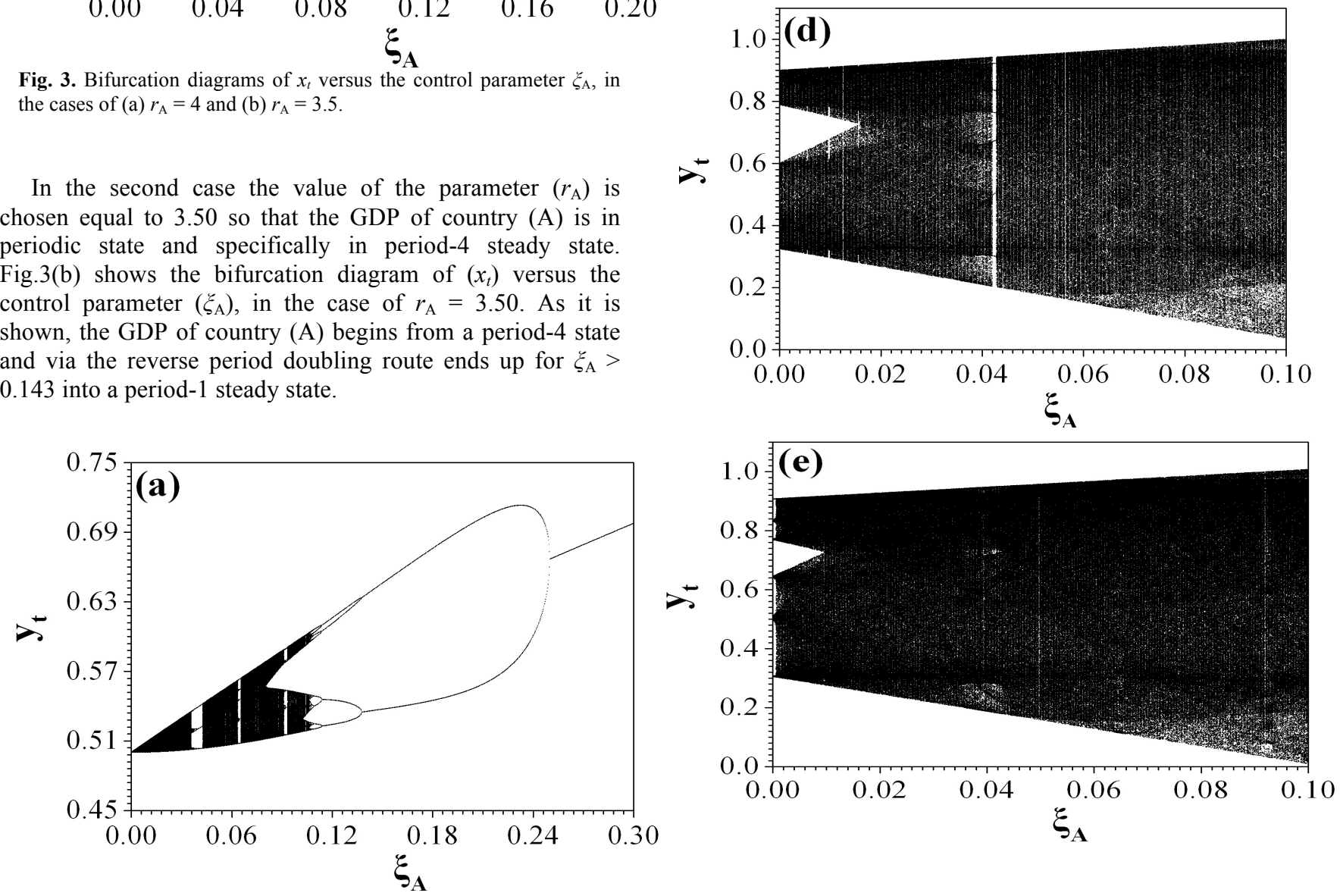


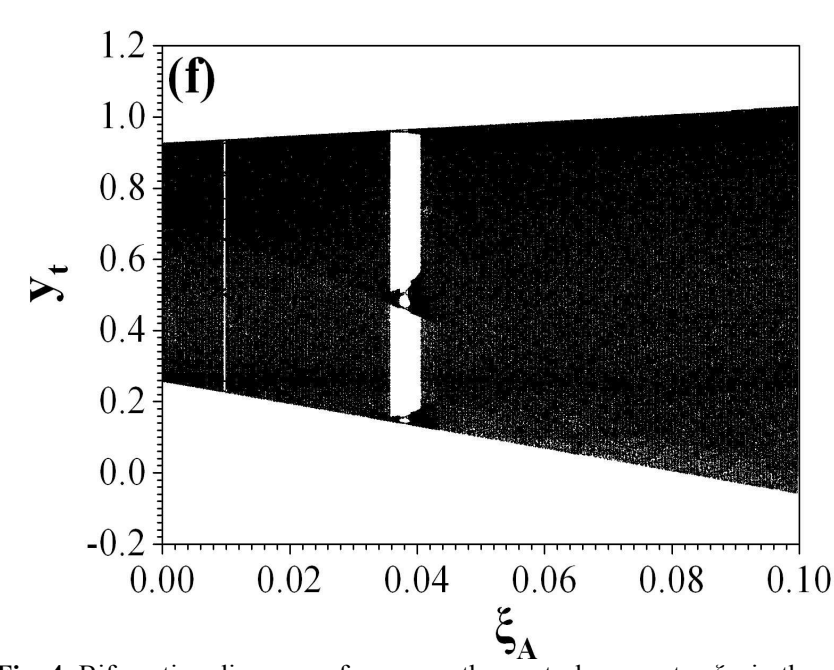

Fig. 4. Bifurcation diagrams of $y_{t}$ versus the control parameter $\xi_{\mathrm{A}}$, in the cases of $r_{\mathrm{A}}=4$, and (a) $r_{\mathrm{B}}=2.00$, (b) $r_{\mathrm{B}}=3.20$, (c) $r_{\mathrm{B}}=3.50$, (d) $r_{\mathrm{B}}=$ $3.60,(\mathrm{e}) r_{\mathrm{B}}=3.63$ and (f) $r_{\mathrm{B}}=3.70$.

Figs.5(a)-(c) display the bifurcation diagrams of $\left(y_{t}\right)$ versus the control parameter $\left(\xi_{\mathrm{A}}\right)$, for three different values of $\left(r_{\mathrm{B}}\right)$ lower than the chosen value of $r_{\mathrm{A}}=3.50$. In the first case, for $r_{\mathrm{B}}=2.00$ (period-1), the very interesting phenomenon of "antimonotonicity" [26] is observed. The GDP of country (B) begins from period- 1 state and through the route: period- $1 \rightarrow$ period- $2 \rightarrow$ period- 1 as the control parameter $\left(\xi_{\mathrm{A}}\right)$ increases, a "primary bubble", as it is named due to its shape, is formed. For $r_{\mathrm{B}}=3.20$ (Fig.5(b)) the GDP of country (B) begins from a period-2 behavior and each branch is driven via the wellknown phenomenon of period doubling to chaos. Finally, in Fig.5(c) a much more complicated behavior for $r_{\mathrm{B}}=3.45$ (period-4) is displayed. The system begins from a period-4 state, same as the economy (A), and via the period doubling ends up to a chaotic region, which suddenly stops and the system with the phenomenon of "crisis" changes its state from chaotic to periodic (period-8) and follows again the aforementioned period doubling route.
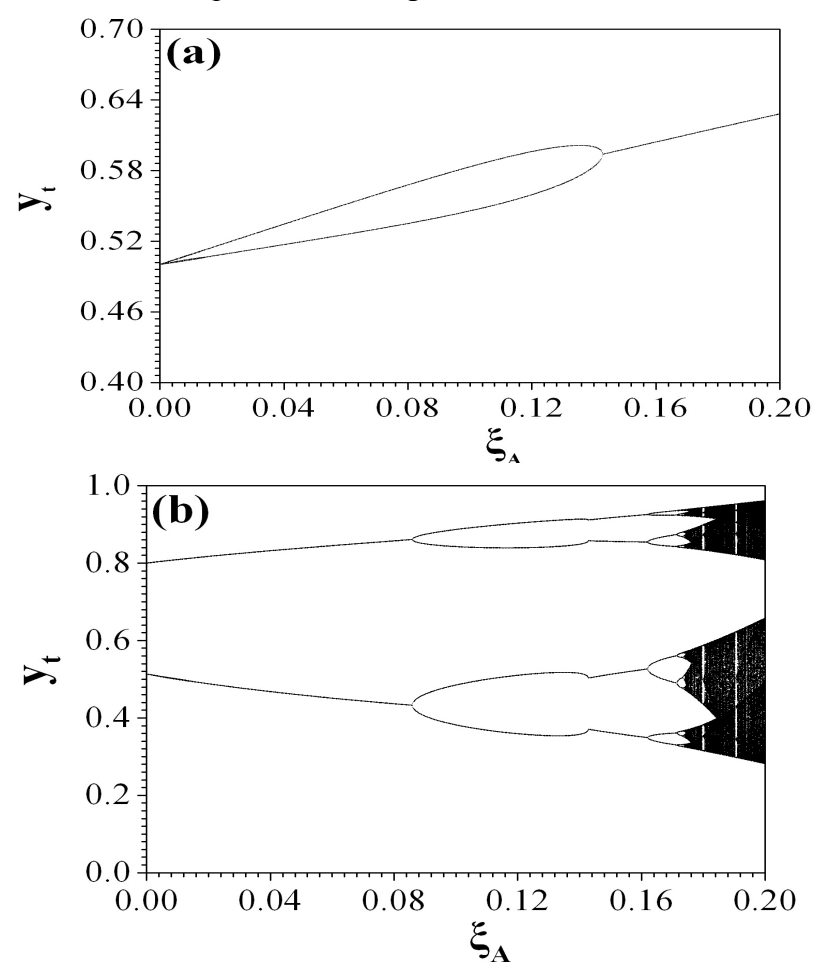

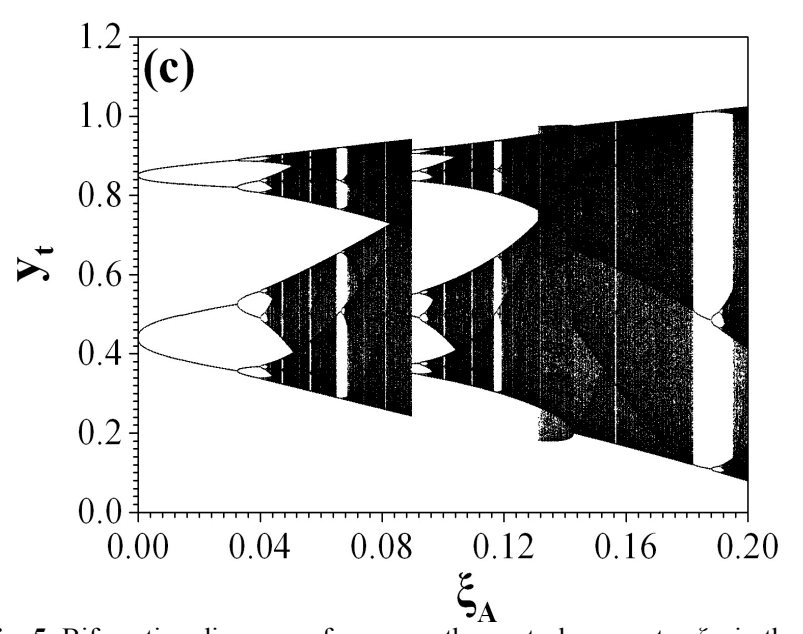

Fig. 5. Bifurcation diagrams of $y_{t}$ versus the control parameter $\xi_{\mathrm{A}}$, in the cases of $r_{\mathrm{A}}=3.5$ and (a) $r_{\mathrm{B}}=2.00$, (b) $r_{\mathrm{B}}=3.20$ and (c) $r_{\mathrm{B}}=3.45$.

\section{Conclusion}

In this paper, the effect of foreign direct investments of an industrialized, economically powerful and technologically advanced country (source country) to a developing country (host country) was studied by using the Logistic map, as a model of the evolution of the gross domestic product. The strong influence of the economy of the source country into the economy of the host country was confirmed.

Two interesting cases, depending on the parameter $\left(r_{\mathrm{A}}\right)$ of the Logistic map representing the source country were studied. In the first case, the gross domestic product of the source country had a chaotic behavior, which means that it can be altered in an unpredictable way from time to time. However, this unpredictability is transferred through foreign direct investments in the host country and affect in the same way the evolution of its gross domestic product, especially for small values of the parameter $\left(r_{\mathrm{B}}\right)$ in host country. For larger values of the parameter $\left(r_{\mathrm{B}}\right)$ the chaotic behavior of the host country's gross domestic product is expanded, so that the this country can follow a different path than the source country according to the conditions prevailing in this country.

In the second case, the gross domestic product of the source country had a periodic behavior, which means that it can follow a predictable route in time. For small values of the parameter $\left(r_{\mathrm{B}}\right)$ the gross domestic product of host country had also periodic behavior different from that of source country, while for larger values chaotic behavior was displayed, which was widened with the increase of $\left(r_{\mathrm{B}}\right)$. 


\section{References}

[1]. E. Borensztein, and J. De Gregorio, Journal of International Economics 45, 115 (1998)

[2]. K.H. Zhang, Contemporary Economic Policy, 19(2), 175 (2001).

[3]. A. Medio, Chaotic Dynamics: Theory and Applications to Economics, Cambridge University Press: Cambridge, (1993).

[4]. J.H. Poincaré, Acta Mathematica 13, 1 (1890).

[5]. E.N. Lorenz, J. Atm. Sciences 20, 130 (1963).

[6]. P.S. Laplace, Traité du Mécanique Céleste. Oeuvres complètes de Laplace, Gauthier-Villars: Paris, (1825).

[7]. R.M. May, and A.R. McLean, Theoretical Ecology: Principles and Applications, Blackwell: Oxford, (2007).

[8]. C. Kyrtsou, and C. Vorlow, Complex Dynamics in Macroeconomics: A Novel Approach, Springer Verlag: Berlin, p.223 (2005).

[9]. B. Van der Pol, and J. Van der Mark, Nature 120, 363 (1927).

[10]. L.W. Casperson, In: Proc. of the NATO Advanced Study Institute, Springer Verlag, p.83 (1988).

[11]. R.J. Field, and L. Györgyi, Chaos in Chemistry and Biochemistry, World Scientific Publishing: Singapore, (1993).

[12]. G.L. Baker, Chaotic Dynamics: An Introduction, Cambridge University Press: Cambridge, (1996).

[13]. F.C. Moon, Chaotic Vibrations: An Introduction for Applied Scientists and Engineers, Wiley, (1987).
[14]. B. Hasselblatt, and A. Katok, A First Course in Dynamics: With a Panorama of Recent Developments, University Press: Cambridge, (2003).

[15]. R.M. May, Nature 261, 459 (1976).

[16]. P.F. Verhulst, In: Mem. Acad. Royale Belg. 20, p.1 (1847).

[17]. D. Mihailović, M. Budinčević, D. Kapor, I. Balaž, and D. Perišić, Natural Science 3(1), 75 (2011).

[18]. L. Wang, F.P. Wang, and Z.J. Wang, Acta Physica Sinica 55, 3964 (2006).

[19]. E.M.F. Curado, and M.A. Rego-Monteiro, Phys. Rev. E 61(6) 6255 (2000).

[20]. V.D. Jablanovic, Advances in Management \& Applied Economics 3(4), 89 (2013).

[21]. T.S. Parker, and L.O. Chua, Practical Numerical Algorithms for Chaotic Systems, Springer-Verlag: New York, (1989).

[22]. R. Findlay, Quarterly Journal of Economics 92, 1 (1978).

[23]. J.Y. Wang, Journal of International Economics 29, 255 (1990).

[24]. R. Levine, and D. Renelt, American Economic Review 82, 942 (1992).

[25]. C. Grebogi, E. Ott, and J.A. Yorke, Phys. Rev. Lett. 48, 1507 (1982).

[26]. S.P. Dawson, C. Grebogi, J.A. Yorke, I. Kan, and H. Kocak, Phys. Lett. A 162, 249 (1992). 